\title{
Anaplastic myxopapillary ependymoma in an infant: Case report and literature review
}

\author{
Darshan Trivedi, Zhenggang Xiong* \\ Department of Pathology and Laboratory Medicine, Tulane University School of Medicine, New Orleans, LA, USA.
}

\begin{abstract}
Summary A 7-month-old boy presented with gastrointestinal disturbance, mild neurologic deficit of the left lower extremity and levo-scoliosis of the thoracic spine. Magnetic resonance imaging demonstrated a large intramedullary lesion involving the thoracic spine, from level T1 to T11. Histologic analysis showed a glial tumor with fibrillary processes arranged in radial pattern around mucoid fibrovascular cores with a high proliferative index (focally up to $80 \%$ ) and prominent vascular endothelial hyperplasia. These findings were consistent with an anaplastic myxopapillary ependymoma. Subtotal resection was performed via a T3-T10 laminoplasty. A ventricular shunt was placed, and the patient subsequently received chemoradiation therapy. To date, this is the second case of a myxopapillary ependymoma with high-grade anaplastic features and the first case in an infant reported in the literature.
\end{abstract}

Keywords: Myxopapillary ependymoma, anaplasia, infant

\section{Introduction}

Myxopapillary ependymoma is considered a lowergrade variant of ependymoma with fibrillary cells arranged in a papillary configuration around a mucoid fibro-vascular cores (1). Of those patients affected by this lesion, typically $66 \%$ are males, with an average age of incidence of 36 years, although the age range of presentation can be between 6 and 82 years. Patients usually present with low-back pain, often with a long progressive course. Nerve impingement is rare and can be indolent due to the lesion's typically slow growth (2). Myxopapillary ependymomas mostly occur in the area of the conus medullaris, cauda equina and filum terminale of the spinal cord. They are the most common intramedullary lesion of this region (1-3). Imaging typically shows a well-circumscribed neoplasm that may have cystic or hemorrhagic features. In the instance of hemorrhagic change, cauda equina syndrome may be

Released online in J-STAGE as advance publication April 30, 2017.

*Address correspondence to:

Dr. Zhenggang Xiong, Section of Neuropathology, Department of Pathology and Laboratory Medicine, Tulane University School of Medicine, 1430 Tulane Avenue, SL-79, New Orleans, LA, 70112-2699, USA.

E-mail: zxiong@tulane.edu the presenting feature (4).

Although the World Health Organization classifies conventional ependymomas as grade II lesions due to the obstructive symptoms that manifest from occlusion of cerebrospinal fluid flow in the ventricles leading to hydrocephalus with injury to the peri-ventricular brain parenchyma, myxopapillary ependymomas are considered as grade I lesions with their slow growth, high rate of total resections and the relatively low rate of serious sequelae. The survival rate is $98.4 \%$ for those patients who have had either a total or subtotal resection. Adjuvant radiotherapy improves progression-free survival $(3,5)$. Anaplastic myxopapillary ependymomas are featured by high grade histopathological changes such as increased mitotic activity, necrosis, vascular endothelial hyperplasia. These tumors are clinically more aggressive.

\section{Case Report}

\subsection{Clinical history}

A 7-month-old boy was initially seen by his primary care provider for concern of stool impaction. X-ray at that time showed levo-scoliosis (curvature of the spine to the left) of the thoracic spine. The patient was treated symptomatically and discharged home. Two months later, his mother noticed decrease movement, stiffness, 
asymmetry and episodes of discoloration of the left lower extremity. MRI showed an intramedullary solid and cystic tumor extending from T1-T11 (Figure 1),

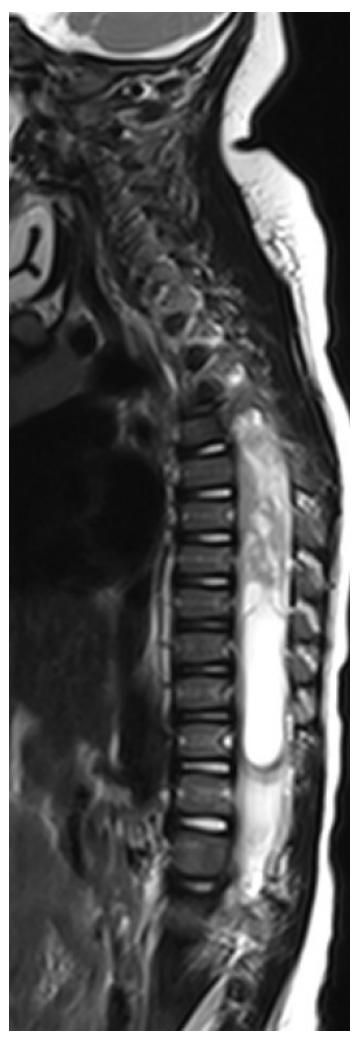

Figure 1. Magnetic Resonance Imaging, T2-weighted, of the thoracic spine lesion extending from level T1 to T11. with associated edema involving the cervico-medullary junction to L1. The patient's condition rapidly worsened with bilateral paralysis and loss of sensation of the lower extremities. A subtotal resection was performed with laminoplasty of T3-T10. Ventricular drainage was initially placed to treat hydrocephalus. This was later revised to a ventriculo-peritoneal shunt. The patient's subsequent course was complicated only by a selfresolved episode of metapneumonia infection. The patient was discharged after one month in the pediatric intensive care unit. At that time, he had regained only limited movement and sensation of the lower extremities. Chemotherapy and radiation therapy were initiated at an outside hospital.

\subsection{Histopathology}

Examination of the lesion using hematoxylin and eosin staining showed a well-vascularized glial lesion with fibrillary processes. There was mucoid degeneration around the vasculature. The fibrillary processes were seen extending through the peri-vascular mucoid matrix and contacting the outer wall of the blood vessels. Vascular endothelial proliferation was observed (Figure 2A). Immunohistologically, the tumor was positive for glial fibrillary acid protein (GFAP) indicative of a glial origin (Figure 2B). Epithelial membrane antigen (EMA) was focally positive, highlighting ependymal cells ringing vasculature. These neoplastic cells also focally expressed pan-cytokeratin, which is a common feature of myxopapillary ependymomas
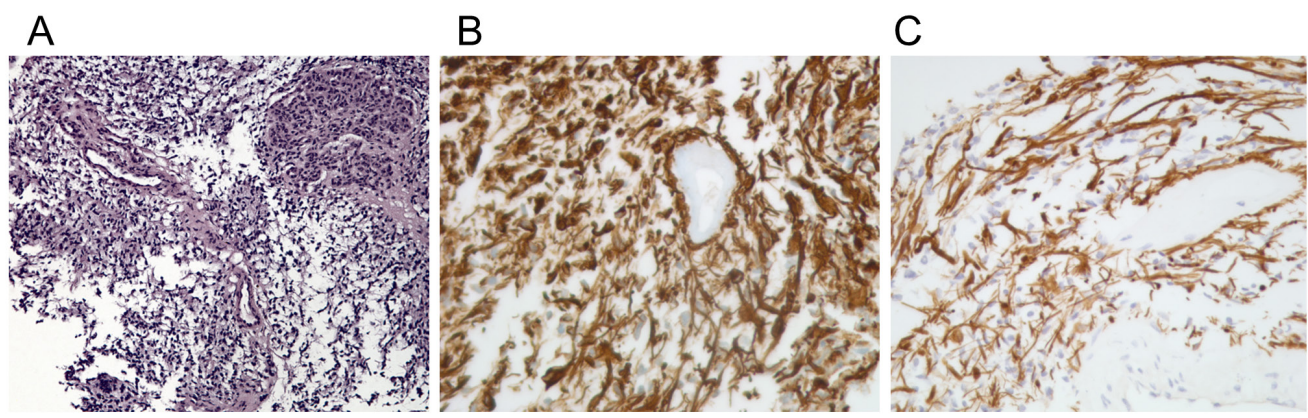

D

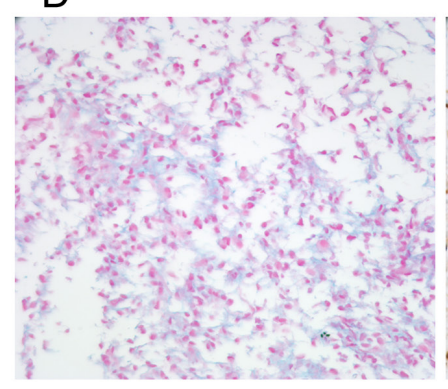

E

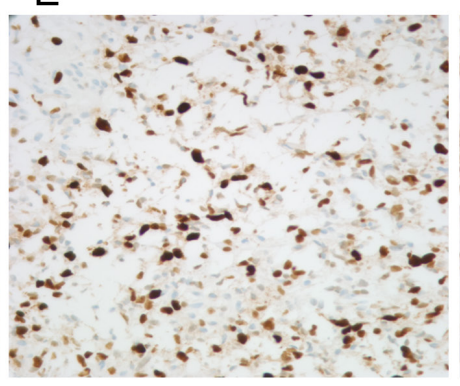

$\mathrm{F}$

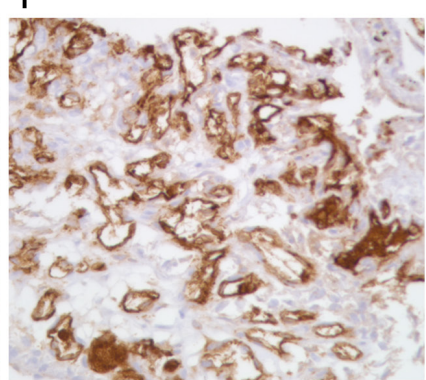

Figure 2. The morphological pattern and immunohistochemical profiles. (A) The lesion demonstrated regions of mucoid degeneration with fibrillary glial processes extending from vascular walls. Focal vascular endothelial proliferation was seen. H\&E, 200×. (B) The lesion demonstrated glial fibrillary acid protein (GFAP) positivity. ( C) The lesion demonstrated pan-cytokeratin (PAN-CK) staining. (D) Mucoid matrix was highlighted by Alcian Blue. (E) Ki-67 immunostaining demonstrated an increased proliferative index. (F) CD31 immunostaining demonstrated endothelial proliferation. 
(Figure 2C). The mucoid component of the lesion was clearly visualized using both alcian blue and periodic acid Schiff staining (Figure 2D). Proliferative index measured by Ki-67 immunohistochemistry was very high and focally reached $80 \%$ (Figure $2 \mathrm{E}$ ). CD31 immunohistochemistry confirmed the vascular endothelial proliferation (Figure 2F). The morphological pattern and immunohistochemical profile are consistent with anaplastic myxopapillary ependymoma (6).

\section{Discussion}

Anaplastic features include increased mitosis, necrosis and vascular endothelial hyperplasia (1). Up to this time, there has only been one prior report of these findings in a myxopapillary ependymoma (7). That prior case occurred in a 15-year-old boy and extended from T12 to L2. The tumor had extensive necrosis and glomeruloid vascular proliferation, the later characteristic being consistent with the case presented in our report. The proliferative index was lower (10.1\%) than our case, but significantly higher than would be expected in a conventional myxopapillary ependymoma. It is worth to note that myxopapillary ependymoma is typically seen in the region of conus medullaris, cauda equina and filum terminale. Interestingly, both tumors in the previously reported case and our case are located in the thoracic and lumbar regions of spinal cord. Both patients are children. Whether this higher spinal cord location and the young age of patients are the unique features of anaplastic myxopapillary ependymoma remains unclear and requires more cases for further study.

Recent genetic analysis of myxopapillary ependymomas found that these lesions are characterized by genome-wide polyploidy, often among several chromosomes $(1,8)$. The excellent outcomes of subtotal resection are often attributed to this significant genetic instability. The specific familial, epigenetic or environmental cause predisposing to anaplastic transformation of this lesion has not been identified. Genetic studies could not be fully carried out in this case due to financial concerns of the family.

Myxopapillary ependymomas can present with spine deformation clinically. Levo-scoliosis is common in the lumbar spine, but its occurrence in the thoracic spine is an early indicator of a thoracic spinal cord neoplasm (9). Early recognition of levo-scoliosis in the thoracic region could potential spare patients from severe neurological sequelae, particularly for pediatric patients.

In general, gross total resection is the best predictive factor of outcomes for conventional myxopapillary ependymoma. These lesions can be difficult to resect completely and recurrences are common following subtotal resection. Distant spinal metastases were found in $9.3 \%$ of patients and brain metastases in $6 \%$ of patients (10-13). Patient age (increased risk with younger age), lack of adjuvant radiotherapy and subtotal resection were the strongest factors predisposing to spread of the lesion (5). Expression of endothelial growth factor receptor (EGFR) has been cited as a possible biomarker of recurrence (14).

This report documents a case of anaplastic myxopapillary ependymoma and is contributory to understanding this rare neoplasm.

\section{Acknowledgements}

The authors would like to thank Dr. Jeremy Nguyen for contributing the radiographic image.

\section{References}

1. Louis DN, Ohgaki H, Wiestler OD, Cavenee WK, Ellison DW, Figarella-Branger D, Perry A, Reifenberger G, von Deimling A. WHO Classification of Tumours of the Central Nervous System ( $4^{\text {th }}$ edition). IARC, Lyons, France, 2016.

2. Cervoni L, Celli P, Caruso R., Gagliardi FM, Cantore GP. Neurinomas and ependymomas of the cauda equine. A review of the clinical characteristics. Minerva Chir. 1997; 52:629-633.

3. Kurt E, Zheng PP, Hop WC, van der Weiden M, Bol M, van der Bent MJ, Avezaat CJ, Kros JM. Identification of relevant prognostic histopathologic features in 69 intracranial ependymomas, excluding myxopapillary ependymomas and subependymomas. Cancer. 2006; 106:388-395.

4. Tait MJ, Chelvarajah R, Garvan N, Bavetta. Spontaneous hemorrhage of a spinal ependymoma: A rare cause of cauda equina syndrome: A case report. Spine. 2004; 29:E502-505.

5. Weber DC, Wang Y, Miller R, Villà S, Zaucha R, Pica A, Poortmans P, Anacak Y, Ozygit G, Baumert B, Haller G, Preusser M, Li J. Long-term outcome of patients with spinal myxopapillary ependymoma: Treatment results from the MD Anderson Cancer Center and instutions from the Rare Cancer Network. Neuro Oncol. 2015; 17:588-595.

6. Ang LC, Taylor AR, Bergin D, Kaufmann JC. An immunohistochemical study of papillary tumors in the central nervous system. Cancer. 1990; 65:2712-2719.

7. Awaya H, Kaneko M, Amatya VJ, Takeshima Y, Oka $\mathrm{S}$, Inai K. Myxopapillary ependymoma with anaplastic features. Pathology Int. 2003; 53:700-703.

8. Pajtler KW, Witt H, Sill M, et al. Molecular classification of ependymal tumors across all CNS compartments, Histopathological grades, and age groups. Cancer Cell. 2015; 27:728-743.

9. Bouaziz MC, Daghfous S, Ladeb MF. Childhood scoliosis revealing spinal tumors. Euro J Ortho Surg \& Trauma. 2006; 16:318-321.

10. Libório R, Pais RF, Soares GB, Rocha A, Ferreira F, Garcia T, Pais FF. Medullary and intracranial metastases of myxopapillary ependymomas. Acta Med Port. 2001; $14: 133-138$

11. Mavroudis C, Townsend JJ, Wilson CB. A metastasizing ependymoma of the cauda equine: Case report. J Neurosurg. 1977; 47:771-775. 
12. Woesler B, Moskopp D, Kuchelmeister K, Schul C, Wassmann H. Intracranial metastasis of a spinal myxopapillary ependymoma: A case report. Neurosurg Rev. 1998; 21:62-65.

13. Yücesoy K, Ozer E, Koyuncuoglu M. Parenchymal brain metastasis of a spinal myxopapillary ependymoma after extradural manipulation. Acta Neurochir (Wein). 2001;
143:1071-1072.

14. Verma A, Zhou H, Chin S, Bruggers C, Kestle J, Khatua $\mathrm{S}$. EGFR as a predictor of relapse in myxopapillary ependymoma. Pediatr Blood Cancer. 2012; 59:746-748.

(Received March 16, 2017; Revised April 17, 2017; Accepted April 21, 2017) 